\title{
Obtenção e avaliação de propriedades tecnológicas de corpos cerâmicos à base de argila e vidros reciclados
}

\section{(Production and evaluation of technological properties of ceramic specimens based on the mix clay-recycled glass)}

\author{
K. O. Godinho, J. N. F. Holanda, A. G. P. da Silva \\ Grupo de Materiais Cerâmicos, LAMAV, Universidade Estadual do Norte Fluminense \\ Av. Alberto Lamego, 2000, Campos dos Goytacazes, RJ 28013-600. \\ angelus@uenf.br
}

\begin{abstract}
Resumo
Pós de rejeitos de três diferentes tipos de vidro foram incorporados a uma massa cerâmica usada na fabricação de telhas. A influência do tipo de vidro adicionado, da quantidade adicionada, do tamanho de partícula de vidro, do método de mistura do aditivo à massa argilosa e da temperatura de queima sobre a tensão de ruptura à flexão, a absorção de água e a retração linear foi investigada. Verificou-se que a adição de vidro atua na queima no sentido de aumentar a tensão de ruptura e a retração linear e de diminuir a absorção de água. Quanto maior a quantidade adicionada de vidro mais intenso é este efeito. O vidro de tubo de TV influencia as propriedades mais marcantemente devido ao maior teor de óxidos fundentes. O tamanho de grão e o modo de mistura do vidro agem sobre a dispersão do aditivo na massa argilosa. As propriedades de queima satisfizeram as especificações de telha e de pisos semiporoso, semi-grês e grês em diferentes temperaturas de queima.
\end{abstract}

Palavras-chave: cerâmica vermelha, telhas e revestimentos, incorporação de resíduos, vidros.

\begin{abstract}
Three different kinds of waste glass powders were added to a clayey formulation used for the production of roof tiles. The influence of the glass composition, the added amount, the glass powder particle size, the glass - clay mixture technique and the sintering temperature upon the bending strength, the water absorption and the linear shrinkage was investigated. The glass additions increase the bending strength and the linear shrinkage while the water absorption decreases. The more the glass amount added to the formulation the more intense is this effect. The glass of TV cathodic ray tube is the most influent addition due to the high amount of flux in its composition. Particle size and mixture technique are related to the dispersion of the additive in the clayey formulation. The properties fulfilled the roof tiles, wall tiles, semi-gres and gres specifications at different firing temperatures.
\end{abstract}

Keywords: clayey formulations, roof and floor tiles, waste glass recycling.

\section{INTRODUÇÃO}

Produtos de cerâmica vermelha representam uma área de grande potencial para incorporação de resíduos [1]. Algumas razões para isto são: enorme volume de produção, envolvendo grande volume de matérias primas; longa vida útil destes produtos; capacidade de encapsulamento dos resíduos incorporados, inertizando resíduos não poluentes; e tolerância que possui os produtos de cerâmica vermelha e seu processamento a variações de composição de suas matérias-primas. Isto viabiliza a incorporação de quantidades razoáveis de resíduos à composição de massas empregadas no fabrico de produtos cerâmicos para construção civil.

Os produtos de vidro são, em princípio, totalmente re-aproveitáveis seja através de re-utilização, como o reenvasamento de garrafas, seja pela sua reciclagem para a fabricação de novos produtos de vidro. Apesar disso, enormes quantidades de vidro são dispostos em aterros, sem o desejável re-aproveitamento. Para estes casos, torna-se necessário encontrar alternativas tecnológicas viáveis que permitam a reciclagem destes vidros de forma econômica e ecológica.

Há inúmeros estudos sobre a incorporação de resíduos de vidro em produtos diversos. Em um estudo sobre o efeito da incorporação de pó de vidro de embalagem ao cimento, foi verificado que se o pó de vidro é fino, ele pode substituir o cimento em certa proporção, sem prejuízo das propriedades [2]. Em outro estudo [3], pó de vidro foi incorporado a cimento asfáltico. Observou-se que a incorporação do vidro nas quantidades investigadas não comprometeu o desempenho do produto. Se de um lado a adição de vidro diminuiu a estabilidade do cimento asfáltico, tornando-o mais suscetível à deformação quando sob carga, por outro lado, aumentou a reflexão de luz à noite e o atrito, fatores associados à segurança do tráfego.

A incorporação de resíduo de vidro a produtos fabricados à base de argila é uma alternativa considerada natural devido à compatibilidade entre a composição química destes produtos 
e a do vidro. Foi relatado [4] que a incorporação de resíduo de vidro com base em carbonato de cálcio em massa cerâmica para a fabricação de azulejos não provocava mudanças significativas no processamento do material. Adicionalmente, a introdução de vidro em massas do sistema triaxial demonstrou que a temperatura de queima poderia ser diminuída, assim como a resistência mecânica e a absorção de água poderiam ser melhoradas [5]. A adição de até $33 \%$ de vidro de soda ao caulim e outros componentes mostrou-se promissora à fabricação de pisos, queimando-se em $1100^{\circ} \mathrm{C}$ por 1 hora [6].

Em outro estudo [7], feldspato foi substituído em porcelanas por vidro sodo-cálcico proveniente de embalagens. Verificou-se a redução da temperatura de queima e da retração de queima. Concluiu-se que estas formulações poderiam ser utilizadas para a maioria das porcelanas.

Vidro sodo-cálcico também foi incorporado em massas cerâmicas usadas na fabricação de telhas e tijolos, seguindo o mais proximamente possível a rotina utilizada industrialmente [8]. Isto resultou em melhoria das propriedades de secagem com a introdução de quantidades de vidro de até $10 \%$ em peso, porém com aumento da absorção de água e diminuição da tensão de ruptura à flexão dos corpos queimados. Novos ensaios com pó de vidro mais fino foram recomendados.

Este trabalho estuda o efeito da incorporação de vidros de diferentes composições sobre as propriedades de queima de uma massa argilosa originalmente empregada na fabricação de telhas. O efeito da adição de diferentes quantidades, tipos e granulometria de vidros em diferentes condições de queima é investigado.

\section{PROCEDIMENTO EXPERIMENTAL}

A argila utilizada neste trabalho é na verdade uma massa constituída pela mistura de argilas industriais de diferentes plasticidades. Esta massa é originalmente empregada para a fabricação de telhas por uma empresa cerâmica da região de Campos dos Goytacazes, RJ. A massa argilosa foi coletada, destorroada e peneirada. Somente a fração passante na peneira de 60 mesh foi usada. A fração retida era uma mistura de torrões mais duros, rochas e matéria orgânica. Em seguida, esta massa foi seca em estufa em $110^{\circ} \mathrm{C}$.

Os vidros utilizados são: vidro de embalagem, vidro plano (de janela) e vidro de tubo de TV a cores, os quais serão identificados doravante como VSCE, VSCP e VPb respectivamente. Os vidros foram inicialmente quebrados, na forma de cacos e depois moídos em moinho de bolas a seco. O tempo de moagem para cada tipo de vidro dependeu dos tamanhos dos cacos originais. Seis horas foram necessárias para a moagem do vidro $\mathrm{VPb}$, que possui os cacos maiores. Após a moagem, o pó foi peneirado e a fração passante na peneira de 60 mesh foi utilizada. Uma outra fração do vidro VSCE, passante na peneira de 20 mesh e retida na peneira de 40 mesh, foi introduzida em uma massa para investigar o efeito da granulometria. Os pós de vidro foram secos em estufa em $110^{\circ} \mathrm{C}$. As composições químicas da massa argilosa e dos vidros foram determinadas por absorção atômica. Os minerais constituintes da massa argilosa foram identificados por difração de raios $\mathrm{x}$. A distribuição granulométrica dos pós da massa argilosa e dos três tipos de vidro foi realizada de acordo com a norma NBR 7181-84 (ABNT), a qual combina técnicas de peneiramento e de sedimentação.

Argila e vidros foram misturados em moinho de bolas, a seco, por $20 \mathrm{~min}$. Nas proporções em peso de 6, 13 e $20 \%$ de cada tipo de vidro. A Tabela I traz as composições de cada massa preparada como percentagem em peso e em volume, dadas as densidades de $2,69 \mathrm{~g} / \mathrm{cm}^{3}, 2,52 \mathrm{~g} / \mathrm{cm}^{3}, 2,54 \mathrm{~g} / \mathrm{cm}^{3}$ e $3,01 \mathrm{~g} / \mathrm{cm}^{3}$ para a argila e os vidros VSCE, VSCP e VPb respectivamente. A massa M0, sem adição de vidro, é usada como referência. Além destas massas, uma outra, com a mesma composição da MTV20 foi preparada sem uso do moinho para a mistura. Neste caso, os ingredientes foram colocados em um recipiente que foi manualmente agitado durante $5 \mathrm{~min}$. O objetivo é investigar o efeito da qualidade da mistura do aditivo. Outra massa, com a mesma composição da ME13 foi preparada com vidro grosso (passante na peneira de 20 mesh e retido na peneira de 40 mesh). O objetivo é investigar o efeito da granulometria do vidro adicionado.

Os limites de Atterberg das massas M0, ME20 e MTV20 foram obtidos segundo as normas NBR 6459-84 (limite de liquidez) e NBR 7180-84 (limite de plasticidade), e a partir destes limites o índice de plasticidade foi também obtido, para se quantificar a influência da adição de vidro sobre a plasticidade das massas.

As massas foram, em seguida, umidificadas com 7\% em peso de água e prensadas em matriz uniaxial de seção retangular, sob pressão de $25 \mathrm{MPa}$. Os corpos prensados

Tabela I - Composições das massas utilizadas. [Table I - Compositions of the pastes]

\begin{tabular}{cccccc}
\hline \multicolumn{2}{c}{ MASSA } & ARGILA & VSCE & VSCP & VPb \\
\hline M0 $\%$ peso & 100 & - & - & - \\
& $\%$ vol & 100 & - & - & - \\
ME6 \% peso & 94 & 6 & - & - \\
\%vol & 93,62 & 6,38 & - & - \\
ME13 \% peso & 87 & 13 & - & - \\
\% vol & 86,24 & 13,76 & - & - \\
ME20 \% peso & 80 & 20 & - & - \\
\% vol & 78,94 & 21,06 & - & - \\
MP6 \% peso & 94 & - & 6 & - \\
\% vol & 93,69 & - & 6,31 & - \\
MP13 \% peso & 87 & - & 13 & - \\
\% vol & 83,38 & - & 13,62 & - \\
MP20 \% peso & 80 & - & 20 & - \\
\% vol & 79,13 & - & 20,87 & - \\
MTV6 \% peso & 94 & - & - & 6 \\
$\%$ vol & 94,60 & - & - & 5,40 \\
MTV13\% peso & 87 & - & - & 13 \\
$\%$ vol & 88,22 & - & - & 11,78 \\
MTV20\% peso & 80 & - & - & 20 \\
$\%$ vol & 81,74 & - & - & 18,26 \\
\hline
\end{tabular}


Tabela II - Ciclos de queima das massas cerâmicas. $\mathrm{T}_{\text {máx. }}=$ 900,975 e $1050{ }^{\circ} \mathrm{C}$.

[Table II - Firing cycle of the clayey pastes. $T_{\text {Max. }}=900^{\circ} \mathrm{C}$, $975^{\circ} \mathrm{C}$ and $1050^{\circ} \mathrm{C}$.]

\begin{tabular}{lccc}
\hline passo & $\begin{array}{c}\mathrm{T} \\
\left({ }^{\circ} \mathrm{C}\right)\end{array}$ & $\begin{array}{c}\text { taxa de } \\
\text { aquecimento } \\
\left({ }^{\circ} \mathrm{C} / \mathrm{min}\right)\end{array}$ & $\begin{array}{c}\text { tempo de } \\
\text { isoterma } \\
(\mathrm{min})\end{array}$ \\
\hline 1 & T. Ambiente -600 & 2 & - \\
2 & 600 & - & 60 \\
3 & $600-$ T. máxima & 2 & - \\
4 & T. máxima & & 120 \\
5 & T. máxima - 600 & -10 & - \\
6 & 600 - T. Ambiente & -1 & - \\
\hline
\end{tabular}

foram secos em estufa por $24 \mathrm{~h} \mathrm{em} 110{ }^{\circ} \mathrm{C}$. A fração volumétrica de poros dos corpos verdes, determinada a partir das densidades verde e teórica, pouco varia para as diferentes massas, permitindo a comparação direta da retração de queima dos corpos destas massas.

Os corpos foram queimados em forno tipo mufla, seguindo um ciclo de queima lento, conforme descrito na Tabela II. As temperaturas máximas são de $900{ }^{\circ} \mathrm{C}, 975^{\circ} \mathrm{C}$ e $1050^{\circ} \mathrm{C}$. As temperaturas máximas de queima foram escolhidas tendo a massa argilosa como referência. As temperaturas de patamar escolhidas estão no extremo superior e um pouco acima do intervalo de temperatura utilizado na Região para a fabricação de telhas.

Após a queima, foram determinadas a retração de queima, a absorção de água e a tensão de ruptura à flexão. Para a retração linear, usou-se a relação $(\mathrm{A})$, em que $\mathrm{L}_{\mathrm{S}}$ é o comprimento do corpo-de-prova seco e $\mathrm{L}_{\mathrm{Q}}$ é o comprimento após queima. A determinação da absorção de água seguiu a norma NBR 6480 (ABNT). A tensão de ruptura à flexão seguiu a norma C674-77 (ASTM). Trata-se de um carregamento em três pontos com taxa de carregamento de $0,5 \mathrm{~mm} / \mathrm{min}$. Cinco corpos de prova foram utilizados para cada massa em cada condição de queima. A estrutura de alguns corpos-deprova queimados foi observada por microscopia eletrônica de varredura com o objetivo de revelar o comportamento do vidro durante a queima.

$$
\mathrm{RL}=\frac{\mathrm{L}_{\mathrm{s}}-\mathrm{L}_{\mathrm{q}}}{\mathrm{L}_{\mathrm{q}}} \cdot 100
$$

\section{RESULTADOS}

Caracterização das matérias-primas: A Tabela III exibe as composições químicas da massa argilosa e dos vidros em termos de percentual em peso dos óxidos constituintes, mais a perda ao fogo. Nota-se o quanto a massa argilosa usada é pobre em óxidos fundentes $\mathrm{K}_{2} \mathrm{O}, \mathrm{Na}_{2} \mathrm{O}$, exceto $\mathrm{Fe}_{2} \mathrm{O}_{3}$. Isto permite prever dificuldades de sinterização em fase líquida. A adição de qualquer tipo de vidro a esta massa eleva os teores de óxidos fundentes. Do ponto de vista da sinterização $\mathrm{da}$ estrutura, isto é positivo, em princípio. $\mathrm{O}$ vidro $\mathrm{VPb}$ possui grande quantidade de $\mathrm{PbO}$ que desempenha papel de fundente e mantêm a viscosidade do vidro em um determinado patamar em um largo intervalo de temperatura.

A Fig. 1 exibe as curvas de distribuição de tamanho de grão da massa argilosa e dos vidros. O pó de argila é o mais fino de todos. Quanto aos vidros, o VPb é o mais grosso.

A difração de raios $X$ do pó da massa argilosa revela ser da caulinita os principais picos de difração. Baseando-

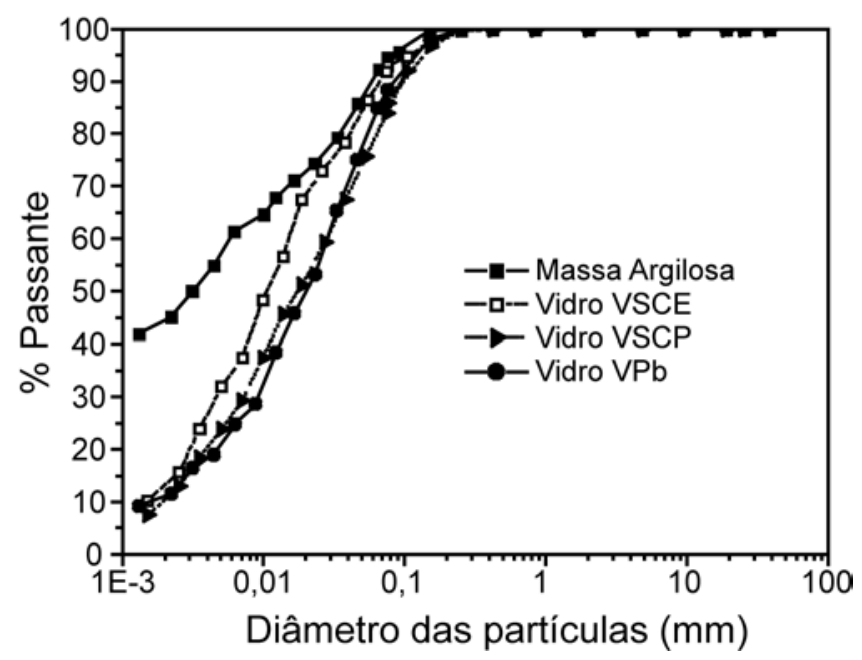

Figura 1: Curvas de distribuição de tamanho de partículas para a argila e os vidros adicionados.

[Figure 1: Particle size distribution curves of the raw materials.]

Tabela III - Composição química das matérias-primas utilizadas (\% em peso).

[Table III - Chemical composition of the raw materials (wt.\%).]

\begin{tabular}{lllllllllll}
\hline Amostras & $\mathrm{SiO}_{2}$ & $\mathrm{Al}_{2} \mathrm{O}_{3}$ & $\mathrm{Fe}_{2} \mathrm{O}_{3}$ & $\mathrm{TiO}_{2}$ & $\mathrm{CaO}$ & $\mathrm{MgO}$ & $\mathrm{K}_{2} \mathrm{O}$ & $\mathrm{Na}_{2} \mathrm{O}$ & $\mathrm{PbO}$ & P.F. \\
\hline Argila & 46,26 & 26,14 & 12,09 & 0,65 & 0,16 & 0,95 & 1,75 & 0,65 & $<0,01$ & 11,3 \\
VSCE & 67,49 & 0,90 & 0,09 & 0,05 & 12,6 & 0,10 & 0,79 & 16,65 & $<0,01$ & 0,51 \\
VSCP & 65,75 & 0,66 & 0,12 & $<0,01$ & 12,5 & 3,05 & 0,74 & 16,71 & $<0,01$ & 0,48 \\
$\mathrm{VPb}$ & 48,60 & 1,68 & 0,11 & 0,01 & 2,80 & 1,80 & 7,68 & 7,31 & 24,96 & 0,67 \\
\hline
\end{tabular}

P.F.: Perda ao fogo 
Tabela IV - Limites de consistência de Atterberg das massas cerâmicas (\% em peso).

[Table IV - Atterberg's plasticity parameters of the clayey pastes (wt.\%).]

\begin{tabular}{cccc}
\hline Massas & $\begin{array}{c}\text { Limite de } \\
\text { Liquidez } \\
(\%)\end{array}$ & $\begin{array}{c}\text { Limite de } \\
\text { Plasticidade } \\
(\%)\end{array}$ & $\begin{array}{c}\text { Índice de } \\
\text { Plasticidade } \\
(\%)\end{array}$ \\
\hline ME0 & 55 & 26 & 29 \\
ME20 & 44 & 23 & 21 \\
MTV20 & 44 & 22 & 22 \\
\hline
\end{tabular}

se neste fato e na literatura $[9,10]$, a caulinita pode ser apontada como o principal mineral presente. Outros minerais identificados são quartzo, goetita, gibsita e mica/mucovita. Este último é a principal fonte de $\mathrm{K}_{2} \mathrm{O}$ da argila.

A Tabela IV exibe o resultado dos limites de Atterberg das massas M0, ME20 e MTV20. As massas ME20 e MTV20 foram escolhidas por serem aquelas de maior teor de vidro, tendo estes vidros diferentes granulometrias.

As transformações ocorridas durante a queima pelos minerais presentes na massa argilosa em uso são bem conhecidas [11]. Dentre elas destacam-se as decomposições da gibsita e da goetita, a desidroxilação da caulinita, a partir da qual passa a denominar-se metacaulinita, e o posterior aparecimento de mulita a partir da metacaulinita. Difrações de raios X realizadas após queima da massa argilosa nas três temperaturas de queima corroboram os relatos da literatura, como mostrado na Fig. 2, que exibe ainda a difração desta massa crua. Difrações feitas em

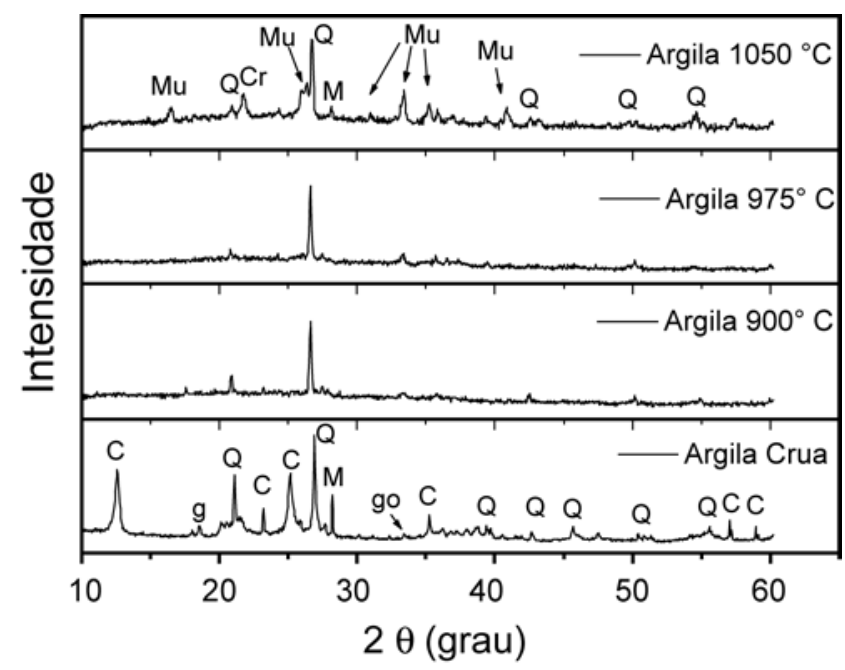

Figura 2: Difratogramas de argila crua e argila queimada em diferentes temperaturas. Foram identificados picos de difração das fases: caulinita $(\mathrm{C})$, goetita $(\mathrm{go})$, gibsita $(\mathrm{g})$, quartzo $(\mathrm{Q})$, mica/ muscovita (M), cristobalita $(\mathrm{Cr})$ e mulita $(\mathrm{Mu})$.

[Figure 2: X-ray diffraction patterns of the as received and the as fired clay at different temperatures. Peaks of the following phases were identified: $(C)$ Kaolinite, $($ go $)$ goetite, $(g)$ gibbsite, $(Q)$ quartz, (M) mica/muscovite, $(\mathrm{Cr})$ cristobalite and $(\mathrm{Mu})$ mullite.] corpos queimados da massa sem aditivo e das massas contendo $20 \%$ em peso de cada tipo de vidro produziram resultados semelhantes em cada uma das três temperaturas de queima. Nos limites de detecção da difração de raios $\mathrm{X}$, não são evidentes o surgimento ou desaparecimento de picos de difração ou ainda a mudança significativa de intensidade dos picos existentes que pudessem caracterizar uma reação entre a argila e os vidros adicionados.

Efeito da adição de vidro sobre as propriedades dos corpos queimados: Tomando a massa sem aditivos como referência, os resultados mostram claramente que a retração de queima e a tensão de ruptura à flexão aumentam com a elevação da temperatura de queima e a quantidade de vidro adicionado, não importando o tipo de vidro, e que a absorção de água tem comportamento inverso. Estas propriedades, entretanto, apresentam variações de comportamento para cada tipo de vidro adicionado.

A Fig. 3(a-c) exibe o comportamento das propriedades de queima em função da temperatura de queima para adições de $6 \%$ de cada tipo de vidro. As Figs. 4(a-c) e 5(a-c) exibem o mesmo para adições de $13 \%$ e $20 \%$ em peso, respectivamente.

As curvas das propriedades apresentam comportamento coerente. A retração linear e a absorção de água estão relacionadas ao nível de sinterização da estrutura. Esta última mede especificamente o volume da porosidade aberta da estrutura. A tensão de ruptura é muito sensível à porosidade, e neste caso, é dominada por ela, pois há uma clara relação entre o aumento da tensão de ruptura e a redução da absorção de água.

O efeito da adição de vidro sobre as propriedades medidas pode ser percebido já com $6 \%$ adicionados, embora não se possa estabelecer uma diferenciação entre os tipos de aditivos. O nível de $18 \%$ de absorção de água, usado como referência para fabricação de telhas, é obtido para a massa argilosa sem aditivo em $975^{\circ} \mathrm{C}$, enquanto que com adição de vidro, este valor pode ser alcançado entre $920^{\circ} \mathrm{C}$ e $950{ }^{\circ} \mathrm{C}$. Com $13 \%$ de adição já se pode perceber que cada tipo de vidro influencia distintamente as propriedades de queima. $\mathrm{O}$ vidro VSCE foi o que mais fortemente influenciou as propriedades de queima, seguindo pelo vidro $\mathrm{VPb}$ e o vidro VSCP. Com a adição de $20 \%$ em peso, esta ordem muda. É o vidro $\mathrm{VPb}$ o de maior influência, seguindo pelo vidro VSCE. Considerando a ordem de influência com $6 \%$ de adição, os vidros VSCE e VSCP apresentam igual influência, seguidos pelo vidro $\mathrm{VPb}$.

Com $20 \%$ de adição, todas as massas adicionadas apresentam absorção de água abaixo de $16 \%$ já a partir de $900^{\circ} \mathrm{C}$ e um mínimo de $2,5 \%$ é atingido pela massa com adição de vidro $\mathrm{VPb}$. A tensão de ruptura mínima especificada para telhas ( $>6,5 \mathrm{MPa}$ ) foi alcançada para todas as formulações estudadas.

Efeito da granulometria do aditivo sobre as propriedades dos corpos queimados: A Fig. 6(a-c) exibe as curvas de propriedades para a massa com adição de $13 \%$ em peso de vidro de embalagem com granulações grossa e fina. Nota-se que as propriedades da massa preparada com vidro grosso são ainda mais pobres do que aquelas exibidas pela massa sem aditivo. Estes resultados estão de acordo com os obtidos 

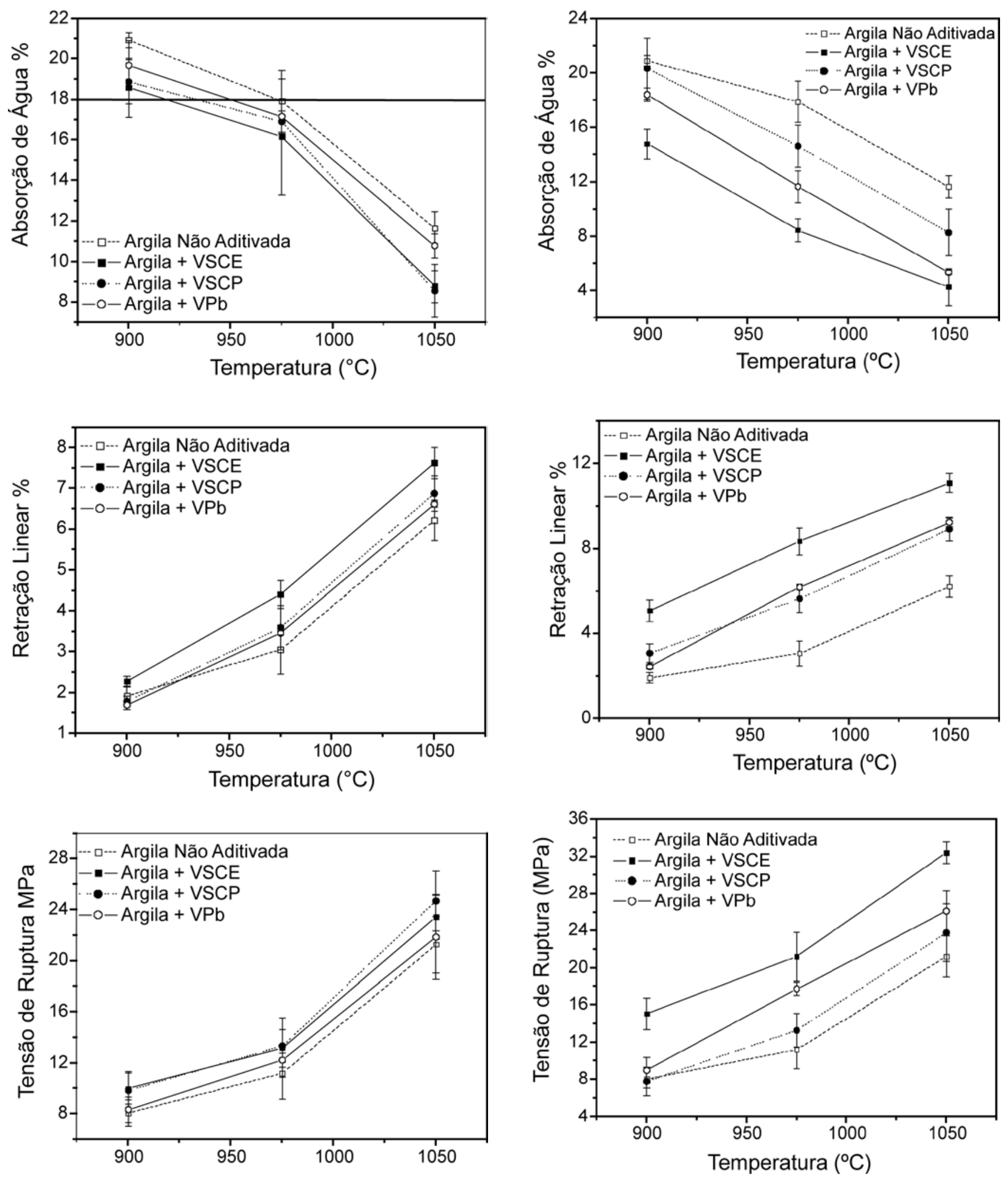

Figura 3: Propriedades de corpos queimados preparados com adição de $6 \%$ em peso dos três tipos de vidro: a) absorção de água, b) retração linear e c) tensão de ruptura à flexão.

[Figure 3: Properties of the fired bodies with addiction of $6 w t . \%$ of the glass powders: a) water absorption, b) linear shrinkage, c) flexural strength.]

Figura 4: Propriedades de corpos queimados preparados com adição de $13 \%$ em peso dos três tipos de vidro: a) absorção de água, b) retração linear e c) tensão de ruptura à flexão.

[Figure 4: Properties of the fired bodies with addiction of 13wt.\% of the glass powders: a) water absorption, b) linear shrinkage, c) flexural strength.] 

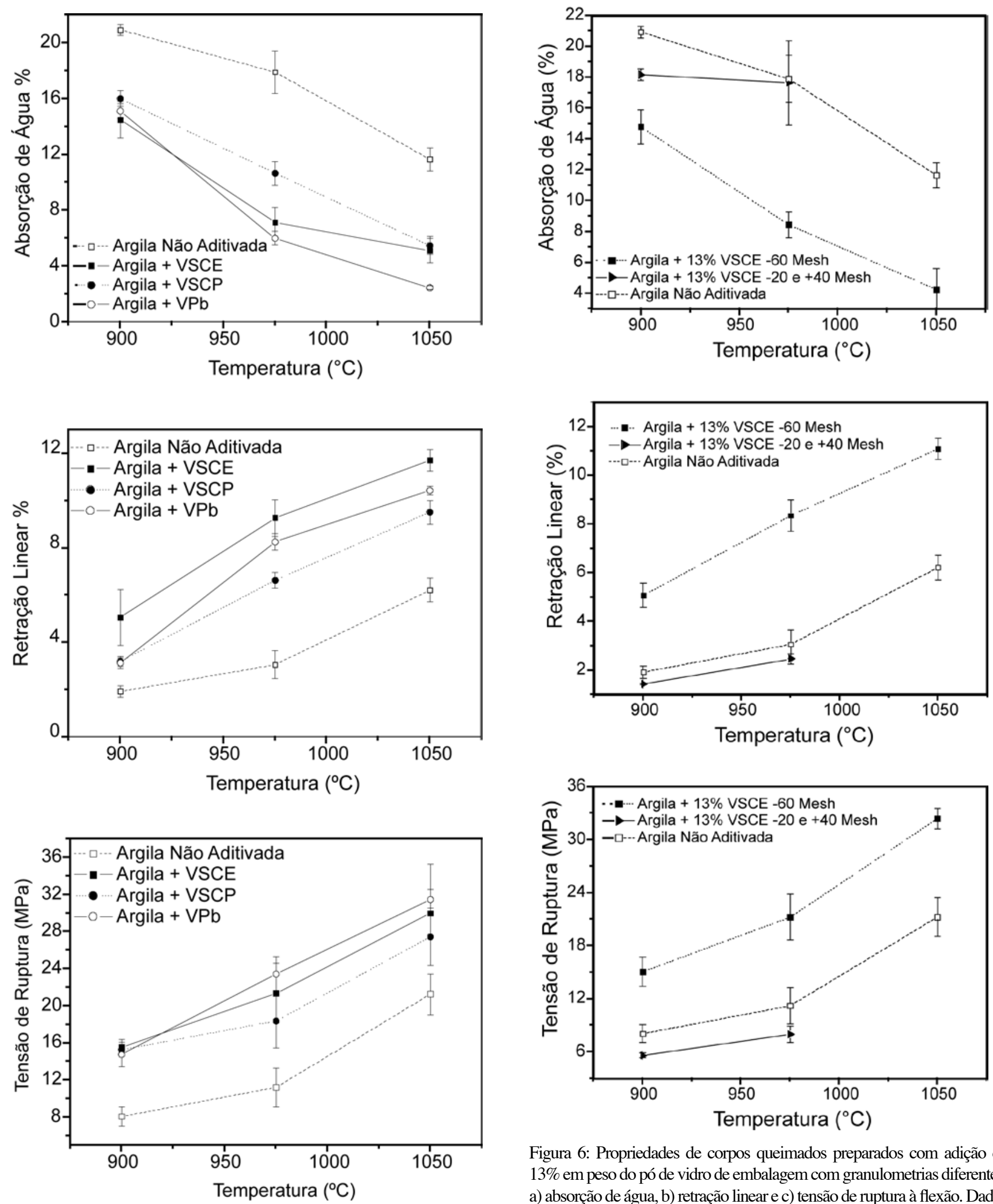

Figura 6: Propriedades de corpos queimados preparados com adição de $13 \%$ em peso do pó de vidro de embalagem com granulometrias diferentes: a) absorção de água, b) retração linear e c) tensão de ruptura à flexão. Dados sobre a massa argila $+13 \%$ VCSE -20 e +40 mesh queimada em $1050{ }^{\circ} \mathrm{C}$ não disponíveis.

Figura 5: Propriedades de corpos queimados preparados com adição de $20 \%$ em peso dos três tipos de vidro: a) absorção de água, b) retração linear e c) tensão de ruptura à flexão.

[Figure 5: Properties of the fired bodies with addiction of $20 \mathrm{wt} \%$ of the glass powders: a) water absorption, b) linear shrinkage, c) flexure strength.]

[Figure 6: Properties of the fired bodies with addition of 13wt.\% of the bottle glass powders with different particle size: a) water absorption, b) linear shrinkage, c) flexural strength. Data on the paste (Clay + 13wt.\% VCSE $-20+40)$ fired at $1050^{\circ} \mathrm{C}$ not available.] 

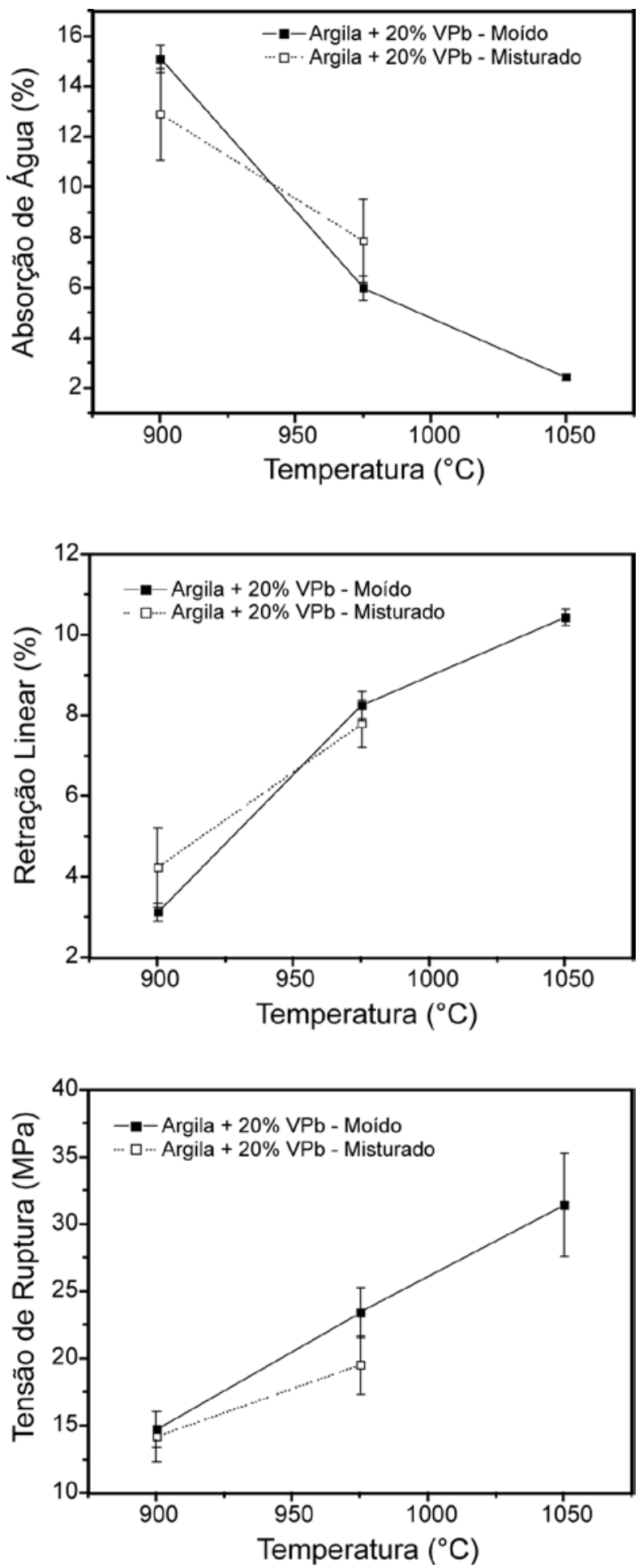

Figura 7: Propriedades dos corpos queimados preparados com adição de $20 \%$ em peso do pó de vidro $\mathrm{VPb}$ misturado de duas maneiras: a) absorção de água, b) retração linear e c) tensão de ruptura à flexão. Dados sobre a massa argila $+20 \% \mathrm{VPb}$ queimada em $1050^{\circ} \mathrm{C}$ não disponíveis.

[Figure 7: Properties of the fired bodies with addition of 20wt\% of the VPb glass powder mixed by different techniques: a) water absorption, b) linear shrinkage, $c$ ) flexure strength. Data on the paste $($ Clay $+20 w t . \% \mathrm{VPb})$ fired at $1050{ }^{\circ} \mathrm{C}$ not available.] em [8], em que pó de vidro de embalagem (sodo-cálcico), com tamanho médio de partícula de quase $200 \mu \mathrm{m}$, foi utilizado.

Efeito do método de mistura do aditivo sobre as propriedades dos corpos queimados: A Fig. 7(a-c) exibe as curvas de propriedades para a massa contendo $20 \%$ em peso de vidro $\mathrm{VPb}$ disperso em moinho de bolas por 20 min e misturado manualmente por $5 \mathrm{~min}$. O comportamento da retração linear e da absorção de água é aproximado para ambos os casos, entretanto as barras de variação para a massa misturada são notadamente maiores de que para a massa moída. Adicionalmente, a tensão de ruptura foi claramente inferior para a massa apenas misturada.

\section{DISCUSSÃO}

A influência da adição de vidro sobre o comportamento plástico da massa argilosa é mostrada na Tabela IV. A massa argilosa sem aditivo M0, com índice de plasticidade de $29 \%$, pode ser considerada de alta plasticidade [12]. Ela é empregada para a fabricação de telhas com conformação por extrusão. A adição de ambos os tipos de vidro diminuiu os limites de Atterberg das massas. Isto ocorre porque os vidros são materiais não plásticos e, quando adicionados, substituem a argila plástica. Entretanto, mesmo $20 \%$ em peso adicionados não reduziram muito a plasticidade das massas. A diferença de granulometria dos vidros adicionados não causou nenhuma influência significativa. A adição de vidro nos teores empregados não deve comprometer a qualidade dos produtos extrudados.

$\mathrm{O}$ efeito das adições de vidro sobre a sinterização da massa argilosa será discutido levando-se em consideração a influência de três fatores: as composições dos vidros, as quantidades de vidros adicionadas e a dispersão dos pós de argila e dos vidros adicionados nas massas preparadas.

Efeito da composição dos vidros: A sinterização de argilas para cerâmica vermelha em temperaturas em torno e acima de $1000{ }^{\circ} \mathrm{C}$ geralmente envolve uma fase líquida que é formada graças à ação de óxidos fundentes presentes na massa argilosa. É esta fase líquida a responsável maior pela sinterização do material. Entretanto, devido à predominância da caulinita na composição mineralógica da argila, a quantidade dos óxidos fundentes principais $\left(\mathrm{K}_{2} \mathrm{O}\right.$ e $\left.\mathrm{Na}_{2} \mathrm{O}\right)$ é pequena. Isto resulta em densificação pobre abaixo de $1050{ }^{\circ} \mathrm{C}$. É esta a origem da dificuldade enfrentada pela indústria cerâmica da região de Campos/RJ de produzir telhas com a argila local queimandose entre $900^{\circ} \mathrm{C}$ e $1000{ }^{\circ} \mathrm{C}$, como é a prática local. Argilas com caráter ilítico, por exemplo, densificam em temperaturas inferiores, devido ao maior teor de $\mathrm{K}_{2} \mathrm{O}$ presente.

Como mostrado na Tabela I, o teor de óxidos fundentes na massa argilosa usada é bastante inferior ao teor destes nos vidros adicionados. A adição de vidros aumentaria, portanto, o teor de fundentes na massa, facilitando a formação da fase líquida na estrutura. Considerando $\mathrm{Na}_{2} \mathrm{O}, \mathrm{K}_{2} \mathrm{O}$ e $\mathrm{PbO}$, que são os óxidos fundentes principais contido nos vidros, o teor total de fundentes nos vidros são $16,92 \%, 17,54 \%$ e $25,27 \%$ molar para os vidros VSCE, VSCP e VPb, respectivamente. Vê-se que os vidros 


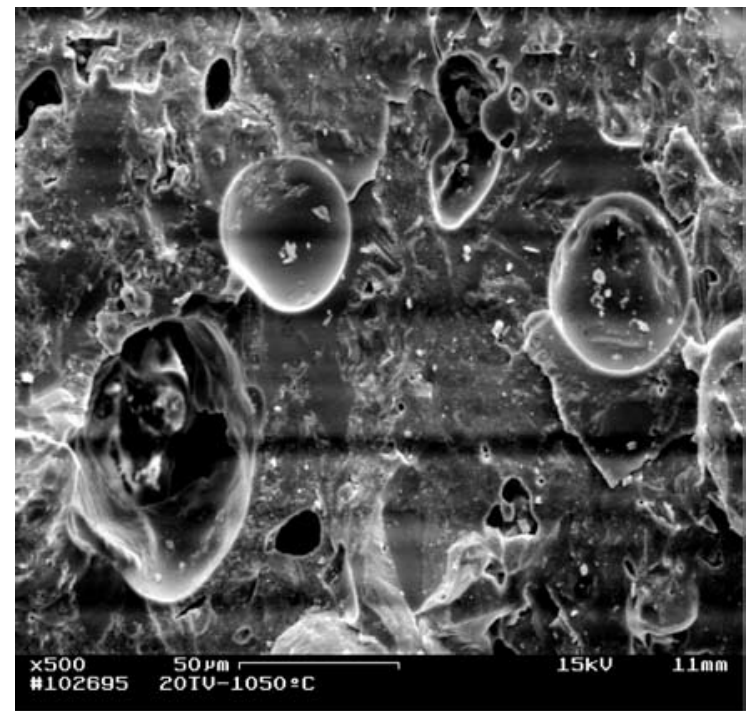

Figura 8: Micrografia obtida por microscopia eletrônica de varredura de um corpo de prova da massa MTV20 queimado em $1050{ }^{\circ} \mathrm{C}$. Estrutura contendo grandes poros arredondados circundados por regiões em alto estágio de densificação.

[Figure 8: SEM micrograph of a body of the MTV20 paste fired at $1050^{\circ} \mathrm{C}$. Large rounded pores surrounded by dense regions are seen.]

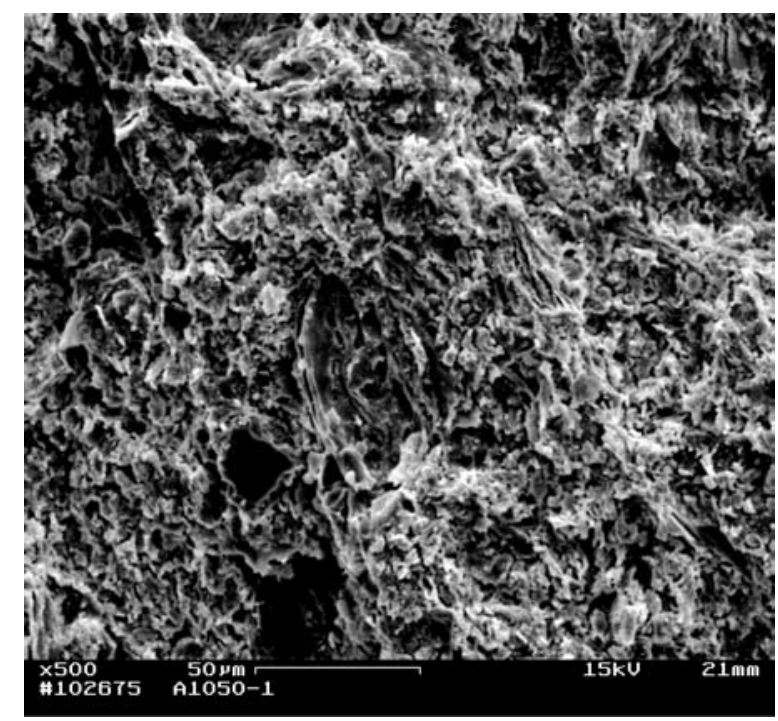

Figura 9: Micrografia obtida por microscopia eletrônica de varredura de um corpo de prova da massa M0 queimado em $1050^{\circ} \mathrm{C}$. Superfície de fratura bastante rugosa, revelando poros e partículas individuais.

[Figure 9: SEM micrograph of a MO body fired at $1050^{\circ} \mathrm{C}$. Rough fracture surface with pores and still discernible particles.]

VSCE e VSCP possuem teores próximos e que o vidro VPb é bastante mais rico em fundentes, sendo esperado comportamento diferenciado dele. Ao vidro $\mathrm{VPb}$ pode estar associada a formação de maior quantidade de fase líquida em temperaturas inferiores.

A Fig. 8 exibe uma imagem da estrutura da massa MTV20 após queima em $1050{ }^{\circ} \mathrm{C}$. Regiões muito densas e poros grandes e arredondados são vistos na estrutura. A Fig. 9 exibe uma imagem da estrutura da massa M0 sinterizada também em $1050{ }^{\circ} \mathrm{C}$. Ambas com a mesma magnificação. Trata-se de uma estrutura com poros muito finos em que as partículas individuais podem ainda ser identificadas. Esta estrutura apresenta um nível de sinterização inferior ao da amostra aditivada, cuja estrutura é mostrada na Fig. 8. A evolução da estrutura de sinterização destas massas em diferentes temperaturas sugere, segundo [13], que a fase líquida é formada pelo vidro amolecido que infiltra os poros da estrutura e que os poros arredondados são formados pelo aprisionamento de gases em poros cujo vidro amolecido isolou do exterior da estrutura.

Efeito da quantidade de vidros adicionados: Embora as quantidades de aditivo sejam dadas em peso, é seu teor em volume que deve ser considerado, levando-se em conta que a fase líquida provêm do amolecimento do vidro. Quanto maior o volume presente de aditivo maior será o volume da fase líquida que promove a sinterização. Como as densidades dos vidros são diferentes, os volumes adicionados são distintos para uma dada adição em peso. Por exemplo, para uma adição de $6 \%$ em peso de vidro, as adições em volume de vidro VSCP e de vidro $\mathrm{VPb}$ são respectivamente $1,1 \%$ e $15,4 \%$ menores de que a de vidro VSCE. Para $20 \%$ em peso de adição, estes valores caem para $0,9 \%$ e $13,3 \%$. Isto significa que o volume de fase líquida é sempre maior para as massas com adição de vidro VSCE, enquanto que o volume de líquido nas massas com adição de vidro $\mathrm{VPb}$ é sempre razoavelmente inferior. Isto pode explicar porquê, apesar do maior teor de fundentes, as adições de vidro $\mathrm{VPb}$ não foram sempre as mais efetivas para a sinterização.

Efeito da dispersão dos pós de argila e de vidro: A dispersão do aditivo na massa argilosa é outro fator a ser considerado. Pode-se definir esta dispersão como a disponibilidade espacial do aditivo através da massa. A dispersão ideal seria aquela em que amostras retiradas de diferentes locais da massa apresentariam igual composição, não importando o quão pequenas elas sejam. Isto implica em uma mistura homogênea entre argila e aditivo. Concentrações locais de aditivo ou de argila representam desvios da boa dispersão e podem ser ocasionadas por aglomerados de partículas de vidro ou argila e por partículas grandes de vidro ou argila. Tais concentrações são responsáveis por sinterização diferencial da estrutura, pois a abundância da fase líquida provoca maior sinterização enquanto que carência de fase líquida acarreta em sinterização deficiente.

Duas técnicas distintas foram empregadas para variar a dispersão do aditivo: a granulometria dos pós de vidro e a forma de mistura dos pós. Com respeito à forma de mistura, a dispersão produzida pela mistura em moinho é superior à dispersão manual. O efeito disto é notável sobre a tensão de ruptura que é menor para amostras feitas com a massa misturada manualmente (Fig.7c). A má dispersão possibilita a existência de locais pobremente sinterizados que atuam como elos fracos da estrutura quando sob tensão. Os valores médios de absorção de água e retração linear não sentiram tanto assim a mudança da técnica de mistura, Figs. 7(a-c). Entretanto, a dispersão destes valores é visivelmente maior para a amostra manualmente misturada, revelando que a boa mistura do aditivo contribui para a reprodutibilidade das 
propriedades dos corpos queimados.

As partículas grandes de vidro representam concentrações locais de líquido. Conseqüentemente haverá carência de líquido em outros locais. Isto explica os resultados exibidos pelas Figs. 6a-c, em que a adição de vidro grosseiro apresentou propriedades mais próximas da amostra sem aditivo de que da amostra com a mesma adição de vidro mais fino. Isto concorda com os resultados relatados em [8]. A granulometria dos três tipos de vidro pode também explicar sua ordem de influência sobre a sinterização.

Potencialidade do uso de rejeito de vidro como aditivo de queima em produtos de cerâmica vermelha: Analisando mais detalhadamente o efeito dos aditivos sobre as propriedades de queima, vê-se que as massas argila rejeitos de vidro também têm potencial para emprego em revestimentos cerâmicos. Foi demonstrado que os rejeitos de vidro desempenham durante a queima um papel que pode substituir parcial ou totalmente os componentes fundentes tradicionais usados nas formulações cerâmicas.

Para a adição de $6 \%$ de rejeito, as especificações de absorção de água $(6,0<\mathrm{AA} \leq 10,0)$ e tensão de ruptura à flexão ( TRF $\geq 18 \mathrm{MPa}$ ), usadas como referência para a fabricação de piso semi-poroso (Grupo BIIb), foram obtidas para as massas argila-VSCE e argila-VSCP, a partir de aproximadamente $1045{ }^{\circ} \mathrm{C}$. Com adição de $13 \%$ de rejeito, diminui a temperatura de queima para a qual estas especificações são alcançadas. Além disso, foram alcançadas as especificações para o piso tipo semi-grês (Grupo BIIa), absorção de água $(3,0<\mathrm{AA} \leq 6,0)$ e tensão de ruptura à flexão ( TRF $\geq 22 \mathrm{MPa}$ ), para a massa argila-VSCE a partir de $1025^{\circ} \mathrm{C}$ e para a massa argila-VPb a partir de $1000{ }^{\circ} \mathrm{C}$.

Com $20 \%$ de adição, as propriedades de queima de piso semi-poroso e semi-grês são alcançadas em temperaturas ainda menores. A massa argila-VSCP também enquadra-se nas especificações de semi-grês a partir de $1050^{\circ} \mathrm{C}$. A maior influência da adição do vidro $\mathrm{VPb}$ sobre as propriedades de queima refletese no fato de que somente a massa com este aditivo alcançou as especificações para o piso tipo grês (Grupo BIb), absorção de água $(0,5 \leq \mathrm{AA}<3,0)$ e tensão de ruptura à flexão ( $\mathrm{TRF} \geq 30$ $\mathrm{MPa}$ ), para temperaturas a partir de aproximadamente $1045^{\circ} \mathrm{C}$.

\section{CONCLUSÕES}

A adição de vidro à massa argilosa influencia sua plasticidade diminuindo os limites de Atterberg, porém, devido à alta plasticidade da massa argilosa empregada, mesmo com a adição de $20 \%$ de vidro a massa ainda apresenta limites de Atterberg elevados.

Nenhum sinal de cristalização do vidro ou formação de fase decorrente de reação entre vidro e argila pode ser observado. Entretanto, a estrutura sinterizada e as propriedades medidas sofrem grande influência da adição de vidros. A fase líquida, responsável pela maior sinterização das estruturas contendo aditivo, pode ser originada do amolecimento do vidro adicionado.
Adições de vidro contribuem para a sinterização da argila, aumentando a retração de queima e a tensão de ruptura à flexão e diminuindo a absorção de água. Quanto maior a adição, mais intenso é este efeito.

Por ser mais rica em óxidos fundentes, a fase líquida formada a partir do vidro $\mathrm{VPb}$ forma-se em menores temperaturas e tende a ser menos viscosa. Isto explica a maior influência deste aditivo em algumas massas. Entretanto, por ser mais denso que os demais tipos de vidro, o teor adicionado, em volume, de vidro $\mathrm{VPb}$ é inferior ao dos demais aditivos. Por isso, para menores teores adicionados, a influência da quantidade de óxidos fundentes não é dominante.

A dispersão do aditivo no pó de argila influencia as propriedades de queima. Concentrações locais sejam de vidro ou de argila, causadas por mistura deficiente ou presença de partículas grandes, levam à queda da tensão de ruptura à flexão e à perda de reprodutibilidade das propriedades.

Os rejeitos de vidro têm potencial para serem utilizados como matéria-prima alternativa na fabricação de produtos cerâmicos.

\section{AGRADECIMENTOS}

Os autores desejam agradecer ao laboratório de Engenharia Civil (LECIV) pelos testes de granulometria das argilas e ao Prof. Eduardo Atem pelos testes de ruptura à flexão.

\section{REFERÊNCIAS}

[1] R. R. Menezes, G. A. Neves, H. C. Ferreira, Rev. Bras. Eng. Agr. Amb. 6, 2 (2002) 303-313.

[2] A. Shayan, A. Xu, Cement and Concrete Res. 34, 1 (2004) 81-89.

[3] Nan Su, J. S. Chen, Resources, Conservation and Recycling 35 (2002) 259-274.

[4] F. Matteucci, M. Dondi, G. Guarini, Ceram. Int. 28 (2002) 873-880.

[5] A. C. Morelli, J. B. Baldo, Cerâmica Industrial 8, 3 (2003) 42-46

[6] N. F. Youssef, M. F. Abadir, M. A. O. Shater, J. Eur. Ceram. Soc. 18 (1998) 1721-1727

[7] S. R. Bragança, C. P. Bergmann, J. Eur. Ceram. Soc. 24 (2004) 2383-2388

[8] A. A. Oliveira, I. R. Carrer, R. H. Corrêa-Silva, F. R. Andrade, H. M. Cardoso, J. M. Couto, V. R. Marcello, Anais $48^{\circ}$ Cong. Bras. Ceram., Curitiba (2004).

[9] F. A. C. Milheiro, M. N. Freire, A. G. P. da Silva, J. N. F. Holanda, Ceram. Int. 31, 5 (2005) 758-760.

[10] J. N. F. Holanda, G. P. Souza, Anais $43^{\circ}$ Cong. Bras. Ceram., Florianópolis, SC (1989) 8201-8210.

[11] G. P. Souza, R. Sanchez, J. N. F. Holanda, J. Thermal Anal. Calorim. 73 (2003) 293-305.

[12] P. S. Santos, Ciência e Tecnologia das Argilas, Vol. 1, $2^{\mathrm{a}}$ Ed., Edgard Blücher, S. Paulo (1989) 408.

[13] K. O. Godinho, Diss. Mestrado, CCT/UENF (2004).

(Rec. 14/02/2005, Rev. 08/04/2005, 04/08/2005, Ac. 05/08/2005) 